\title{
Engineering cell-based therapies to interface robustly with host physiology
}

\author{
Kelly A. Schwarz ${ }^{a}$, Joshua N. Leonard ${ }^{a, b, c, d}$
}

a Department of Chemical and Biological Engineering, Northwestern University, 2145 Sheridan Rd., Evanston, Illinois 60208, United States

b Chemistry of Life Processes Institute, Northwestern University, 2170 Campus Dr., Evanston, Illinois 60208, United States

c Member, Robert H. Lurie Comprehensive Cancer Center, Northwestern University, 675 N. St. Clair, Chicago, Illinois 60611, United States

d Corresponding author: j-leonard@u.northwestern.edu 


\section{Abstract}

Engineered cell-based therapies comprise a rapidly growing clinical technology for treating disease by leveraging the natural capabilities of cells, including migration, information transduction, and biosynthesis and secretion. There now exists a substantial portfolio of intracellular and extracellular sensors that enable bioengineers to program cells to execute defined responses to specific changes in state or environmental cues. As our capability to construct more sophisticated cellular programs increases, assessing and improving the degree to which cell-based therapies perform as desired in vivo will become an increasingly important consideration and opportunity for technological advancement. In this review, we seek to describe both current capabilities and potential needs for building cell-based therapies that interface with host physiology in a manner that is robust - a phrase we use in this context to describe the achievement of therapeutic efficacy across a range of patients and implementations. We first review the portfolio of sensors and outputs currently available for use in cell-based therapies by highlighting key advancements and current gaps. Then, we propose a conceptual framework for evaluating and pursuing robust clinical performance of engineered cell-based therapies.

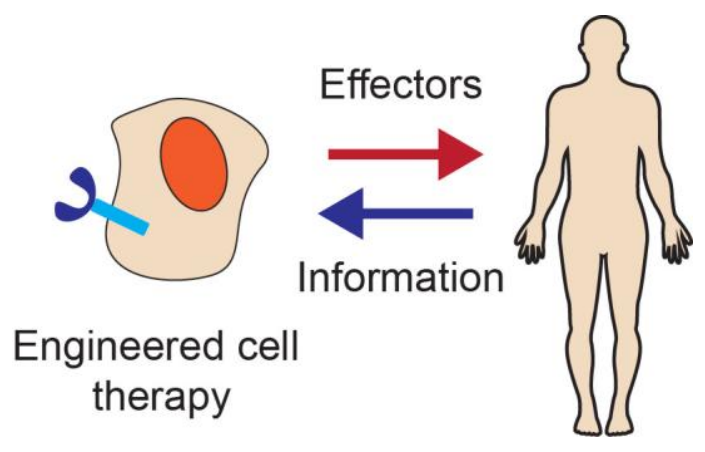

\section{Keywords}

Mammalian synthetic biology

Biosensors

Cell-based therapies

Gene circuits 


\section{Table of Contents}

1. Introduction

2. Modalities for engineering cells to interface with physiology

2.1. Sensors

2.1.1. Intracellular Sensors

2.1.2. Extracellular Sensors

2.2. Outputs

3. Factors impacting the robust performance of cell-based therapies

3.1. Choice of genetic engineering platform

3.1.1. Lentivirus vectors

3.1.2. Adeno-associated virus vectors

3.1.3. Transposons

3.1.4. Genome editing

3.1.5. Human artificial chromosomes

3.2. Achieving host tolerance of engineered cells

4. Strategies and opportunities for achieving robust performance

4.1. Tools for evaluating the performance of engineered cellular functions

4.2. Opportunities for engineering robust cell performance

5. Conclusions and future outlook 


\section{Introduction}

Engineered cell-based therapies comprise a promising and rapidly-expanding frontier in medicine. The potential of this approach is perhaps most clearly illustrated by the mounting clinical successes achieved using engineered immune cells to combat certain types of cancer $[1,2]$. However, cancer immunotherapy represents but one application for which the generation of customized and programmable cellular functions could enable safer, more effective, and functionally sophisticated therapeutic strategies. In this review, we focus on the promise of engineered mammalian cell-based therapies, although therapies derived from engineered bacteria or other non-mammalian cells have also been proposed and have been reviewed elsewhere [3, 4]. Below, we first present a general overview of the types of "parts," from a mammalian synthetic biology perspective, that have been developed and might be utilized to build customized cell-based therapies (Fig. 1). In particular, we focus on the parts that enable an engineered cell to sense and respond to its environment, which we describe as interfacing with host physiology. We next present a conceptual framework for evaluating the degree to which engineered cell-based therapies perform and interface with host physiology in a manner that is robust - a phrase we use to describe the successful execution of a therapeutic "program" even though individual physiology and implementations of any particular strategy may vary between patients. As mammalian synthetic biology technologies transition from pre-clinical to clinical evaluations, such considerations will become increasingly important. We argue that considering such performance criteria, and the technologies required to achieve desired performance, could inform the investigation of new approaches for closing identified gaps and ultimately facilitate the design of new therapies that are both safe and effective. 


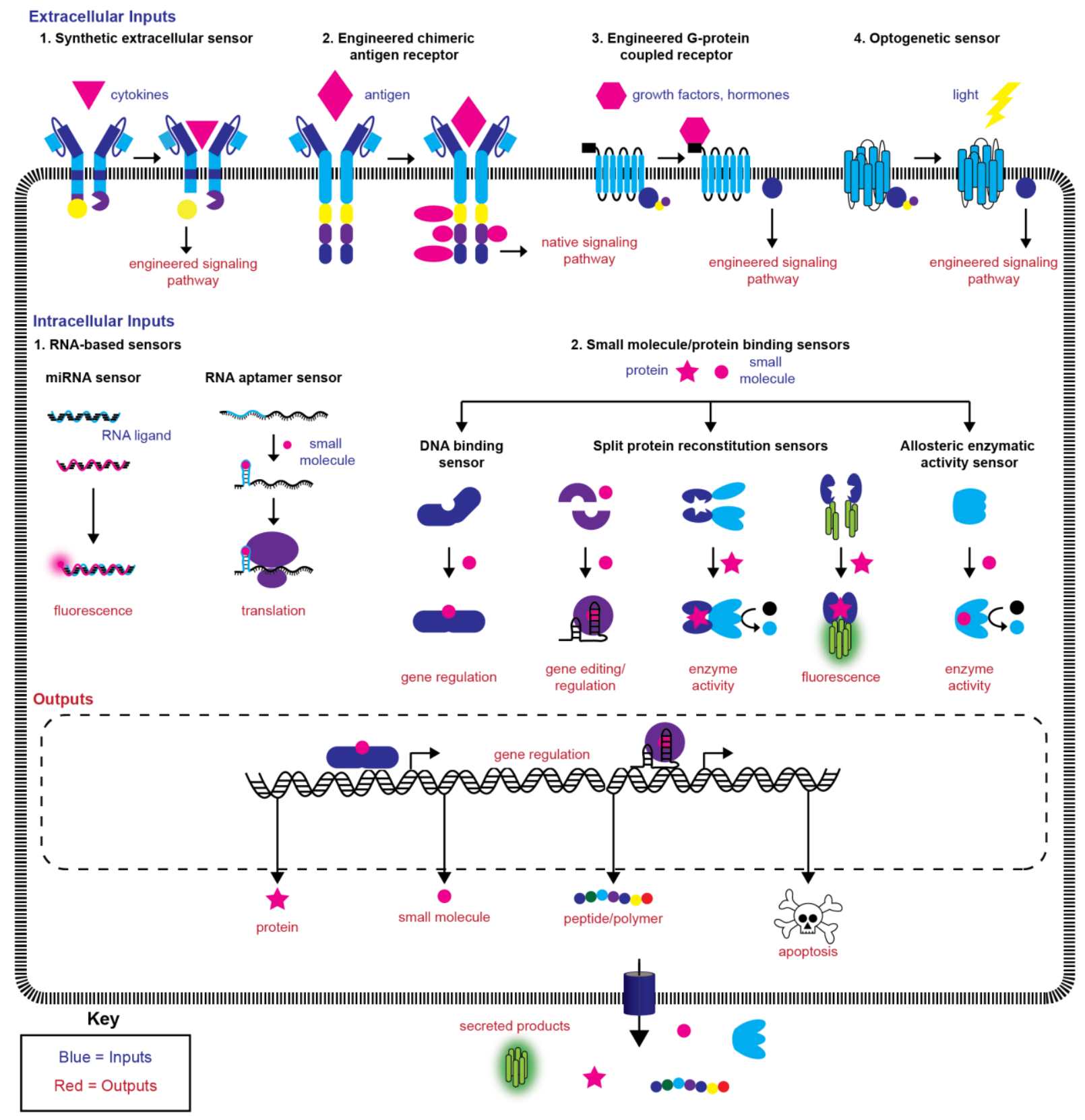

Figure 1: Parts for engineering mammalian cell-based therapies to interface with host physiology. This cartoon summarizes the types of parts currently described for engineering mammalian cell-based therapies to recognize various "inputs" and, in response, generate various "outputs". In this framing, extracellular inputs contain information about the external environment, while intracellular inputs can contain information about either the internal cell state or the environment if such cues are transported into the cytoplasm where sensing occurs. Similarly, outputs of these parts can confer a change in cell state (including regulation of gene expression or induction of apoptosis), modulate the environment via secreted factors, or otherwise generate a signal that can be externally monitored. Each of the examples depicted in this figure is described in detail in the corresponding section of the main text. 


\section{Modalities for engineering cells to interface with physiology}

There now exist numerous tools for engineering cells to sense intracellular and extracellular cues, and in response, to generate outputs that modulate the overall physiological state of the patient or "host". Here, we survey the range of modalities that have and may be used as sensors and outputs for engineering customized cell-based therapies.

\subsection{Sensors}

In general, both proteins and nucleic acids may be engineered into sensors, such that binding of the sensor to small molecules, metabolites, ions, proteins, or other cues results in the production of a user-defined output (summarized in Fig. 1). Since the growing toolbox of proteinand RNA-based sensors has been extensively surveyed elsewhere (e.g., [5, 6]), here we focus our discussion on opportunities for harnessing sensors of intracellular or extracellular ligands to program engineered cell-based therapies.

\subsubsection{Intracellular sensors}

There exists a range of modalities by which sensing of an intracellular ligand (either produced intracellularly of capable of diffusing across the plasma membrane) may be used to control the function of an engineered cell based therapy. First, sensors can enable the regulation of cellular functions through closed-loop control, which confers self-regulating therapeutic functions [7, 8]. Several promising demonstrations of closed-loop control have been reported in which implantable cell-based "devices" were employed to maintain homeostasis via prosthetic gene networks [7-9]. In each of these cases, the presence of an intracellular ligand, which is relevant to the external physiological state, determines whether an engineered transcriptional regulator is recruited to a target DNA sequence encoding a gene that modulates host physiology; thus, such systems achieve real-time monitoring and modulation of the host physiological state. For example, one synthetic cell-based device was employed to sense and reduce the accumulation of uric acid in blood, which can lead to gout and crystal deposits in the kidney [7]. This system utilized a bacterial transcriptional repressor, HucR, which binds to a cognate exogenous DNA motif (hucO) to block transcription in the absence of uric acid. Cells were also engineered to express human urate-anion transporter URAT1, which mediates uptake of extracellular uric acid. Thus, accumulation of uric acid in the extracellular environment led to intracellular accumulation as well, and binding of uric acid to HucR alleviated transcriptional repression of a transgene encoding the enzyme urate oxidase. Finally, expression and secretion of urate oxidase catalyzed the conversion of uric acid to allanotoin, a molecule that is cleared from the body via renal secretion. Implantation of cells engineered to perform this task in urate oxidase-deficient mice reduced uric acid levels $\sim 2.5$-fold, which is comparable to the efficacy of standard drug treatment. In another example, an obesity control device was engineered to monitor fatty acid levels in the blood via a synthetic receptor/transcription factor composed of the native nuclear lipid receptor, peroxisome proliferator-activated receptor- $\alpha$ (PPAR $\alpha$ ), fused to a bacterial DNA-binding repressor, $\operatorname{TgR}$ [8]. PPAR $\alpha$ recruits co-activators in the presence of fatty acids, which in this device was used to drive expression of pramlintide, a peptide hormone that suppresses appetite and slows gastric emptying, thereby attenuating blood lipid levels and combatting weight gain (in this mouse model system, such a device actually induced weight loss). The use of bacterial $\operatorname{TtgR}$ also provided an added feature - a safety switch by which the device can be shut down via the administration of the small molecule phloretin; thus, this system employed both closed-loop control and "external control", the latter of which is discussed in greater detail below. 
Variations on the closed-loop control concept may also be employed to achieve goals other than homeostasis. For example, engineered cell-cell communication may enable consortia of engineered cells to work in concert to confer therapeutic effects. Several systems for engineering communication between "sender" and "receiver" cells have been described, utilizing nitric oxide [10] or acetaldehyde [11] as mediators of communication. In each of these systems, sensing of the mediator occurred in the cytoplasm of receiver cells, such that intracellular binding of the mediator to a sensor protein led to a change in transcriptional regulation of a transgene. Ultimately, engineered cell-cell communication may be combined with sensors responsive to host-derived signals in order to guide processes such as tissue regeneration, in which programmed communication amongst multiple types of host and engineered cells may be required. At the alternative end of the spectrum are concise strategies such as engineered protein therapies that are conditionally active depending on the sensed cell state. This approach is exemplified by Ostermeier et al.'s engineered protein switch which catalyzes pro-drug conversion only upon recognition of cancer-associated hypoxia-inducible factor $1 \alpha(\mathrm{HIF}-1 \alpha)$ [12]. The switch comprised an insertional fusion between the $\mathrm{CH} 1$ domain of $\mathrm{p} 300$ and a prodrug converting enzymatic domain (cytosine deaminase). In this system, a hypoxia-induced conformational change in HIF-1a promoted its binding to the $\mathrm{CH} 1$ domain of the sensor, which then caused cytosine deaminase domain to adopt a catalytically active conformation. RNA aptamer-based sensors can also be engineered to regulate gene expression or guide protein splicing upon ligand-aptamer binding in order to program responses to cell state (reviewed in [5]). For example, RNA controllers have been combined to implement an 'AND' gate, producing an apoptotic protein only upon sensing both $\beta$-catenin and NF-KB [13]. Ultimately, the success of any intracellular sensor relies upon the degree to which the engineered cell assesses the host state, and the toolkit for engineering such assessments is rapidly expanding.

\subsubsection{Extracellular sensors}

Extracellular sensors enable cells to detect environmental cues that are unable to cross the cell membrane. Indeed many of the most informative indicators of the host state are exclusively extracellular, including antigens, cytokines, and growth factors. For some applications, natural cell surface receptors can be directly coopted into engineered functions. One such approach employed hepatocyte growth factor (HGF) as a mediator and was used to generate spatial patterns in 3D cell culture [14]. In this system, MDCK cells, which tubulate in response to HGF, were implanted on a scaffold; cells at one end were engineered to secrete a repressor of HGF signaling (a truncated hepatocyte growth factor variant), inducing a gradient of gene expression across the scaffold with high levels of tubulation at one end and no tubulation at the opposite end. For most applications, however, cell surface proteins must be engineered and have generally been modified by one of three approaches: (1) engineering extracellular ligand-recognition components such that the receptors retain the native intracellular signaling mechanisms but respond to novel ligands, (2) redirecting natural receptors to couple native ligand sensing mechanisms to the induction of signaling via novel downstream pathways, or (3) engineering synthetic receptors that couple the sensing of novel ligands to the induction of intracellular signaling via orthogonal signaling mechanisms (Fig. 1).

Several protein families have been extensively investigated to engineer responsiveness to novel ligands. G-protein coupled receptors (GPCRs), which are seven pass transmembrane proteins that mediate a range of sensing and intercellular communication functions, have been engineered primarily through directed evolution and targeted mutagenesis [15-19]. Some such investigations have generated GPCRs whose activation is induced by inert, small molecule drugs, contributing new tools enabling external control of cellular functions $[15,17]$. The most clinically successful use of engineered extracellular sensors is the development of chimeric antigen receptors (CARs) for use in cancer immunotherapy [1, 2, 20, 21]. CARs achieve 
recognition of tumor antigens via antibody small chain variable fragments (scFvs), and these scFvs are fused to native intracellular domains conferring $T$ cell receptor (TCR)-mediated signaling. The use of scFvs as ligand-binding domains enables CARs to recognize antigens without requiring that the antigens be presented in the context of the major histocompatibility complex (MHC), as would be the case for TCR-mediated antigen recognition. Thus, one CAR can be used for many patients despite their genetic variations in MHC genes. Current generation CARs include multiple engineered intracellular domains, such as CD28, 4-1BB, and CD3 3 co-stimulatory domains, to achieve and augment $T$ cell responses [22, 23]. These therapies first showed great clinical promise by treating B-cell malignancies using anti-CD19 CARs [24, 25], and similar approaches are progressing towards treating other cancers, including solid tumors [26-29]. Given these unequivocally promising results, addressing remaining challenges such as on-target/off-tumor activation and poor activation at the disease site comprise active areas of research [30,31]. To this end, various new CAR designs have been developed that improve safety [32-35], enhance efficacy in the immunosuppressive tumor microenvironment [36, 37], and prevent tumor escape [38, 39]; some of these innovations are discussed in more detail in section 6 , below. One important lesson from the recent proliferation of CAR research activities and clinical trials is that the modularity of CAR design has enabled both rapid extension to novel ligands and iterative refinement of CAR functionality through design-build-test cycles of engineering development.

An alternative to engineering novel ligand specificities is developing extracellular sensors that maintain responsiveness to the native ligand but link that detection to a novel intracellular event. One such approach is the Tango assay, which can be used to monitor ligand binding-induced association between receptors and downstream signaling molecules [40]. In this system, the intracellular portion of the cell surface receptor of interest is genetically fused to a transcription factor via a cleavable linker sequence. The cognate protease is genetically tethered to an adaptor protein that is recruited to the receptor upon ligand binding, leveraging natural mechanisms regulating these conditional protein-protein interactions. Thus, ligand binding-induced association of these proteins causes the protease to cleave its target sequence, releasing a transcription factor to drive expression of a transgene such as a fluorescent protein reporter. Optogenetic sensors provide another example in which native receptor output is redirected to novel signaling cascades, enabling non-invasive control of engineered cell-based therapies post-implantation. One such sensor was used to express glucagon-like peptide 1 in response to blue light, enabling control of blood-glucose homeostasis in diabetic mice [41]. Altogether, rewiring downstream signaling pathways is a facile approach for incorporating evolved ligand-receptor-adapter interactions into engineered cellular functions.

An important characteristic of each of the sensors described above is their utilization of some native signal transduction pathways to relay the sensing event to a change in cell state. While this strategy enables one to use parts that have been tuned through evolution, such an approach also introduces some limitations. Native signaling components may be subject to native mechanisms of regulation and cross-talk, including post-translational modification and protein-protein interactions. Use of native pathways also restricts the number of mechanisms one may use to construct an engineered function, and strategies such as sensor multiplexing may be challenging unless a sufficient number of orthogonal mechanism can be coopted. Therefore, technologies for engineering fully orthogonal sensors that directly couple the detection of external cues to changes in cell state would substantially expand our capacity to engineer customized cellular functions.

Towards this goal, we recently reported the development of a modular extracellular sensor architecture (MESA), which is a self-contained receptor-signal transduction system [42]. Each MESA receptor comprises two engineered transmembrane proteins, one of which includes an intracellular protease domain and the other of which includes an intracellular transcription factor that is initially sequestered at the plasma membrane. The extracellular domains confer 
recognition of a target ligand, such that ligand binding-induced receptor heterodimerization causes a trans-cleavage event that releases the transcription factor to travel to the nucleus. Importantly, this modular mechanism may be readily adapted to confer recognition of novel inputs (by substituting ligand-recognition domains) and regulation of novel outputs (by substituting the transcription factor domain).

Another recently reported strategy for engineering fully orthogonal extracellular sensors leveraged the unique signaling mechanism utilized by Notch receptors (syn-Notch) [43]. Each syn-Notch receptor comprised a Notch core, flanked by modular extracellular and intracellular domains. Binding of syn-Notch receptors to ligands presented on the surface of target cells led to receptor aggregation, which induced protease-mediated cleavage of the Notch intracellular domain via native mechanisms, thereby releasing the engineered intracellular domain. Given this self-contained mechanism, syn-Notch receptors can be multiplexed and connected through genetic logic gates. This point was illustrated through developing a CAR AND gate therapy that conditioned $T$ cell activation upon the presence of two defined ligands [44]. By restricting $T$ cell activation and cytokine release to regions expressing both antigens, the authors successfully demonstrated enhanced conditional activation of a CAR T cell therapy at tumor sites. As the pool of extracellular sensors continues to grow, so does our capacity to engineer cells to recognize and discriminate between defined combinations of environmental cues.

\subsection{Outputs}

In the context of engineered cell-based therapies, "outputs" might be defined as any mechanism by which the engineered cell modulates its environment or other cells in a manner that is controlled by upstream sensing and/or signal processing parts (Fig. 1). In the aforementioned examples of cell-based devices that maintain homeostasis, the peptide hormone pramlintide [8] and the secretion-engineered urate oxidase [7] both comprise outputs. Alternatively, regulated expression of an intracellular enzyme could mediate the generation and secretion of an enzymatic product as an additional form of output, including the case of conditional prodrug conversion discussed above [12, 34, 45, 46]. Ultimately, virtually any secreted small molecule or protein could reasonably be coopted as an output, depending on the requirements of the application. Moreover, there also exist new modalities by which an engineered cell-based therapy may modulate physiology.

A promising and only partially explored mode of output is the conditional modulation of immune function. This application comprises an attractive opportunity for synthetic biology approaches given that control that may be required to balance safety and efficacy of such interventions. While CAR T cell therapies are certainly the most widely implemented version of this strategy, CAR approaches are largely limited to applications in which detection of an immobilized antigen (or antigens) drives T cell activation via some form of TCR signaling. A variation on this strategy is the insertion of a transgene for which expression is driven by TCR signaling, e.g., by using the NFAT promoter, such that binding of the TCR to antigen can be coupled to expression of any desired transgene output [36]. Alternatively, antigen sensing may be redirected to drive alternative endogenous immune pathways, as was demonstrated using a chimeric receptor comprised of antibody-based antigen recognition domains fused to Toll-like receptor (TLR) signaling domains; when dendritic cells expressing such receptors were exposed to the target antigen (in this case, erbB2-expressing tumor cells), TLR-driven inflammation was induced [47]. A particularly exciting frontier is the use of synthetic biology to control the presentation of pathogen-derived adjuvants and antigens in order to generate "smart vaccines," such as those that might be constructed on the basis of RNA replicon systems [48, 49]. Indeed

such nucleic acid-based systems are currently under investigation as vehicles for driving the production of therapeutic levels of recombinant antibodies in situ [50], and if successful, such an approach may also be leveraged as a form of output. 
Finally, newly emerging facets of cell biology and intercellular communication and coordination, such as the seemingly ubiquitous transfer of cellular contents via secreted extracellular vesicles [51, 52], may ultimately enable new modes of output. For example, it is now understood that many tumors secrete extracellular vesicles, which remodel normal tissues to establish pre-metastatic niches at distal sites [53-56]. This remodeling is mediated by the transfer of biomolecules including both proteins and nucleic acids (especially microRNA) from a tumor sender cell to a non-tumor receiver cell. Such mechanisms may ultimately be coopted in cell-based therapies to coordinate complex cellular processes, such as migration, wound healing, and differentiation, all of which are areas of active investigation.

\section{Factors impacting the robust performance of cell-based therapies}

Given the growing list of parts available for engineering mammalian cells, and the diverse strategies for which such parts may be employed, we next consider how to evaluate and improve the performance of cell-based therapies. In particular, we approach this question through the aforementioned concept of robustness - the degree to which an engineered cellbased therapy successfully carries out a therapeutic function across multiple patients and implementations. To frame this discussion, we propose a conceptual model for considering four general sources of heterogeneity that are expected to impact the construction and performance of cell-based therapies (Fig. 2). First, inter-donor heterogeneity may arise when cells are sourced from different donors. Second, inter-recipient heterogeneity reflects the possibility of differential performance when the same cell product is administered to different patients. Third, intra-recipient heterogeneity describes the differential performance of a cell product at different sites within a single patient recipient (including both off-target and on-target effects). Finally, intercellular heterogeneity describes variations in the manner in which individual engineered cells respond to the same environmental cues. For both novel therapies and established therapies, for which there yet exists substantial room for improvement, we anticipate that evaluating and accounting for these sources of variability through engineering design will become increasingly important. In the following sections, we discuss strategies for evaluating heterogeneity and robust performance and for engineering new solutions to increase therapeutic efficacy and improve safety. 


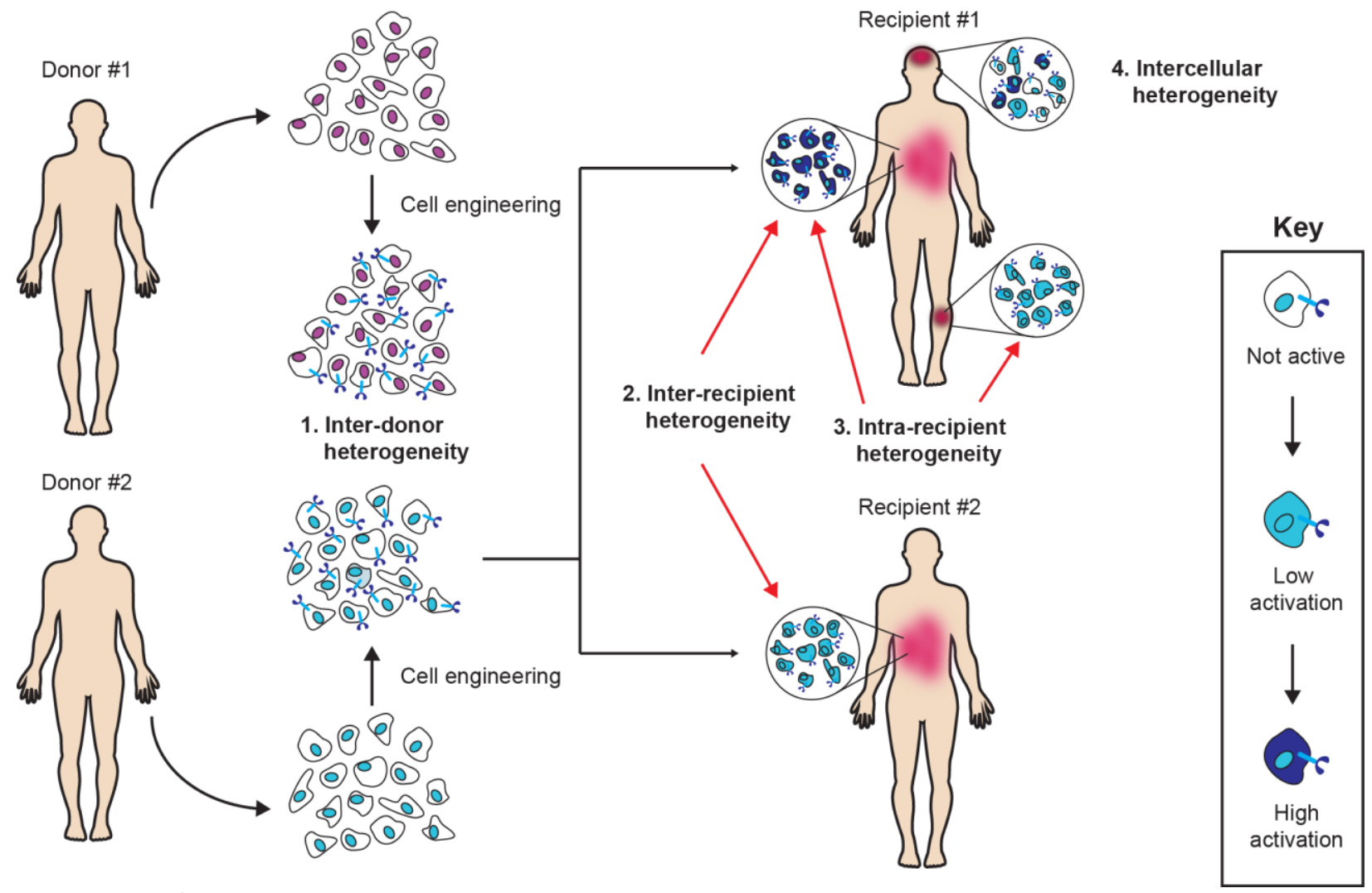

Figure 2: Sources of heterogeneity in cell-based therapies. A conceptual framework for evaluating potential sources of heterogeneity impacting the performance of engineered cellbased therapies, including: (1) inter-donor heterogeneity - variations between cells derived from different donors, (2) inter-recipient heterogeneity - variations between cells administered to different recipients, (3) intra-patient heterogeneity - variations in cellular responses between different sites within one recipient, (4) intercellular heterogeneity - variations between the responses of individual cells in the same environment. Note that in this figure, we use "activation" to generically illustrate an engineered cellular response to environmental cues.

\subsection{Choice of genetic engineering platform}

The choice of method for introducing novel genetic material into a cell will impact many attributes of an engineered cell therapy including efficacy, safety, and longevity. A full discussion of these considerations is beyond the scope of this review, so here we focus specifically on the degree to which the choice of gene delivery system is likely to impact the robustness of an engineered cellular function, particularly in the context of known sources of heterogeneity (Fig. 2).

\subsubsection{Lentivirus vectors}

Lentiviruses are promising therapeutic delivery vehicles, with a large transgene capacity (up to $18 \mathrm{~kb}$, although packaging is maximal for vectors up to $7 \mathrm{~kb}$ ) [57]. These vectors have been used extensively for gene therapy applications, including CAR $T$ cell therapy, and advances in vector design and production have improved performance and safety [58, 59]. Lentiviruses integrate vector DNA permanently into the host cell genome at locations that are 
somewhat random, with some preference for transcriptionally active regions [60]. This random integration confers differential levels of transgene expression, sometimes varying over several orders of magnitude between individual cells within a single population. Moreover, integrated vectors are subject to extensive methylation and may even drive genome-wide epigenetic modification [61-63]. Such differences may explain some variation between cells (intercellular heterogeneity), between individuals (inter-donor and inter-patient heterogeneity), and changes in performance over time. Overall, lentiviral transduction is a therapeutically viable method capable of delivering large payloads, although it confers variable transgene expression levels that may impact the performance of engineered cellular functions.

\subsubsection{Adeno-associated virus vectors}

Transient transgene expression via adeno-associated virus (AAV) vectors is currently a gold standard for gene therapy. AAV is a single-stranded DNA virus, with the capability to transduce multiple tissues and cell types, a cargo capacity of up to $3 \mathrm{~kb}$, and titers that scale well for clinical production [64,65]. The effective transgene size can be increased (e.g., up to 4 $\mathrm{kb}$ ) by delivering two AAV vectors simultaneously, each of which expresses one half of a transgene which is subsequently reconstituted via protein splicing [66]. While lentiviruses are often used for ex vivo transduction of cells prior to reimplantation, AAV is most commonly delivered in vivo. AAV vectors are generally maintained episomally, which can confer extended periods of transgene expression and may even moderate intercellular heterogeneity to some extent. In addition, wild-type AAV can integrate with low frequency into the AAVS1 locus, which is believed to be a safe harbor locus $[67,68]$. Some evidence indicates that AAV vectors integrate at AAVS1 as well [69]. Extrachromosomal maintenance could provide a safety benefit by avoiding insertional mutagenesis, although targeted integration at AAVS1 is also welltolerated. While AAV is non-toxic, because nearly everyone has been exposed to at least one AAV serotype, recognition of the virus by the adaptive immune system can lead to immune rejection of AAV-transduced cells, and evading such rejection is an area of active and promising research (reviewed in [70,71]). Differential immune responses to AAV vectors could also contribute to some inter-recipient heterogeneity in cell-based therapy performance. While AAV has been widely investigated for gene therapy applications, employing AAV for engineering custom cellular functions remains promising, but relatively less explored.

\subsubsection{Transposons}

Transposons provide a non-viral method for moving DNA segments from one location to another and can be harnessed to introduce transgenes into engineered cells. One commonly used transposon system, the sleeping beauty transposon (SBT), utilizes a transposase provided in trans to transfer cargo DNA (up to $10 \mathrm{kB}$ ) from a donor molecule to the host cell chromosome $[72,73]$. SBT is capable of integrating into any genomic location including the sequence, "TA". Given the multitude of TA sites within the human genome, integration is efficient, but transgene expression levels vary by integration site, and as is the case with lentiviral vectors, this variation contributes to intercellular heterogeneity. Furthermore, transgene expression can be transient due to methylation at the SBT integration site [74, 75]. Nonetheless, SBT remains an attractive method for non-viral gene delivery, and improvements in vector design [72], promoter usage [76], and selection of integration location, including the development of landing pad sites [77, 78], could improve this technology and reduce heterogeneity and instability. SBT has shown substantial promise as a gene delivery platform, and there already exists a substantial track record for using SBT to engineer and manufacture cell-based therapies in the form of CAR T cell therapies [79]. However, improvements in the SBT platform are necessary to make it attractive for a wide range of applications. For example, reducing SBT integration location 
heterogeneity could reduce both intra-recipient heterogeneity and inter-recipient heterogeneity in cell-based therapy performance by conferring more consistent levels of transgene expression.

\subsubsection{Genome editing}

Several programmable nuclease platforms have emerged over the last several years as powerful genome editing technologies, including zinc finger nucleases (ZFNs), TALENs, and the CRISPR-Cas9 system [80, 81]. Each system directs nuclease activity to a specific genomic location by using rules to either engineer modular protein domains (ZFNs or TALENs) or to design target-complementary small guide RNAs (sgRNAs, for use with Cas9). Following DNA cleavage, homology-directed DNA break repair is utilized to achieve transgene insertion. From a comparative standpoint, ZFNs are perhaps the most challenging to design and have the lowest success rates ( 10\%), while TALENs and Cas9/sgRNAs are easier to design and have relatively higher success rates ( 20\%) [81]. The Cas9 system is particularly attractive because transgenes may be targeted to virtually any locus of interest without requiring laborious and technically challenging protein engineering, since essentially all specificity is conferred by the sgRNA [82, 83]. However, off-target DNA cleavage by Cas9 could potentially lead to intercellular heterogeneity and reduce the performance of a cell-based therapy. The potential for off-target cleavage has been widely explored [84-87], and developing computational tools and strategies for minimizing potential off-target effects still remains an active area of investigation [88-91]. For example, the use of paired nickases [86, 92, 93], truncated sgRNAs [94], and delivery of purified Cas9 protein instead of Cas9-expressing transgenes $[95,96]$ have limited off-target genome editing. An alternative to nuclease-mediated genome engineering is the use of recombinases to integrate large DNA cassettes into a site of interest [97], although such methods require the use of a genomic "landing pad," which is typically introduced by another method. Landing pads are attractive because effectively all engineered cells could be genetically identical (no intercellular heterogeneity). However, introducing the landing pad complicates cell engineering, as some method must also be utilized for landing pad integration, and it is not clear whether such an approach would be useful or feasible when applied to cellbased therapies based upon primary cells. Given the power and rapid advancement of genome editing technologies, these approaches are likely to drive the prototyping, development, and implementation of engineered cell-based therapies, especially as genome editing is potentially a robust method for gene delivery.

\subsubsection{Human artificial chromosomes}

Human artificial chromosomes (HACs) are independent, replication-competent genetic elements that deliver and maintain very large genetic cargos. Because HACs do not integrate into the host genome, this approach may circumvent problems of transgene silencing and alteration of native gene expression patterns (thereby reducing some sources of inter-recipient and intra-recipient heterogeneity). HACs can be maintained at multiple copies and deliver cargo DNA at the megabase scale [98, 99]. Delivery of HACs to host cells is a challenge, however, and while a few methods have been developed, including polyethylene glycol-mediated fusion and microcell fusion, delivery improvements are needed to achieve a clinically viable HAC technology [98]. Nonetheless, therapeutically relevant genes have been delivered by HACs, including cell surface membrane proteins to correct cystic fibrosis [100], circulating proteins for correcting hematological malignancies [101, 102], and structural proteins for treating muscular dystrophy [103]. HACs are the least developed transgene delivery system discussed here but advancements in HAC production and delivery to host cells may enable widespread use of this promising technology. 


\subsection{Achieving host tolerance of engineered cells}

Since many cellular engineering strategies involve the expression of non-native proteins, one of the major decisions when choosing a cell type is developing strategies for avoiding immune rejection. One solution is to engineer cellular programs using only non-protein parts (e.g., RNA), which generally presents no antigens that are subject to adaptive immune recognition. While RNA parts may be recognized by receptors of the innate immune system, many potential recognition motifs are well-characterized, such that RNA parts may be designed to largely circumvent undesired off-target modulation of endogenous genes [104]. Another solution is to encapsulate the engineered cells in a non-degrading polymer cage, such that the host and engineered cells are in contact via exchange of soluble molecules, but direct contact between host cells and engineered cells is prevented. This approach was utilized in the homeostasis-mediating implants discussed above [7, 41]. A particularly attractive aspect of this approach is the potential to use allogeneic cells, rather than relying upon autologous cells, which could substantially reduce cost and simplify manufacturing processes and regulatory evaluations. An alternative method for avoiding immune rejection, particularly when encapsulation of the engineered cells is not an option, is the induction of active immune tolerance to the engineered proteins and/or cells. While methods for inducing immune tolerance are still in early stages, promising early results have been reported, for example, in the treatment of autoimmune disorders such as type 1 diabetes and multiple sclerosis [105-107]. Conceivably, such approaches could be extended to confer host tolerance of engineered cells expressing exogenous proteins, although whether this is possible and how this consideration may guide the choice of which parts to utilize remains to be investigated.

Another possible solution to the challenge of immune rejection may be to utilize a cell type that is intrinsically resistant to rejection. Red blood cells (RBC) are an attractive option since these cells can be cultured and differentiated in vitro, persist in the body for long periods of time (over $\sim 120$ days), have access to almost all physiological compartments, and lack a nucleus such that aberrant proliferation is not possible [108, 109]. RBC may also be engineered to display a range of functional domains through the use of strategies such as sortase-mediated coupling of proteins and chemicals to engineered RBC surface proteins [108]. Notably, such covalently-modified RBC persisted for more than 28 days in vivo, suggesting that the modified proteins and cells are rather well-tolerated, and whether this duration can be extended further remains to be seen. Additionally, RBC have been used as therapeutics for the treatment of blood disorders such as sickle-cell disease and beta-thalassemia [110-113]. Both diseases are caused by mutations in the hemoglobin gene, reducing the capacity of these patients' RBC to effectively carry oxygen. To treat these diseases, engineered progenitor stem cells were engrafted into the bone marrow niche in order to provide a sustained source of functional hemoglobin. As was the case for pioneering efforts in CAR T cell engineering, investigating each of these questions and opportunities is likely to be driven by specific needs encountered as applications for engineered cell-based therapies continue to proliferate.

\section{Strategies and opportunities for achieving robust performance}

In this section, we consider recent innovations and open opportunities for improving the performance of cell-based therapies, particularly with respect to robustness, as outlined above.

\subsection{Tools for evaluating the performance of engineered cellular functions}

While the conceptual framework described in Figure 2 is intuitively attractive, assessing such sources of heterogeneity and how or whether they impact the performance of an 
engineered cell-based therapy is often nontrivial. However, reported tools and analytical methods provide early insights into how facets of this challenge may be addressed. To date, many of these tools have been used only in pre-clinical settings, yet it is likely that evaluating the performance of cell-based therapies in vitro will enhance our ability to understand key design parameters and principles in order to improve performance in vivo.

When engineering a cell-based therapy that responds to an environment ligand, it would be useful to evaluate how such an engineered cell "sees" or distinguishes between various concentrations of the environmental ligand. To investigate this question in the context of natural cellular pathways, Levchenko et al. pioneered the application of information theory to analyzing intracellular signaling [114]. For example, when such analysis was applied to the natural tumor necrosis factor (TNF) signaling pathway, the authors concluded that most individual fibroblasts responded to various external TNF concentration as if concentration was essentially a binary variable (present vs. absent); in any one cell, this pathway transduces $\sim 1$ bit of information [115]. However, more information is transferred from the environment to cells if bottlenecks are removed (e.g., rate-limiting mass transfer steps), or if one considers cellular responses either integrated over time or collectively (combining the responses of multiple cells). One must exercise some caution in the naïve application of information theory to evaluating cell signaling processes, since to be meaningful, information must not only be transduced by cell signaling pathways, it must be interpretable by downstream cellular processes [116]. All transduction, transcription, and translation processes are associated with some noise, and this impacts the amount of signal that is transmitted. Thus, one must consider the information transduction capacity of a gene, not just an upstream pathway [117]. Moreover, while the molecular mediator of a biological signal may be produced locally by one cell, the downstream interpretation of this signal occurs over time and often requires diffusion of the mediator away from the local environment, resulting in some loss of information. Overall, the information theory framework may facilitate both the design and analysis of cellular programming strategies that filter environmental information in a manner that leads to desirable engineered cellular responses.

Computational design software is an increasingly essential engineering tool for synthetic biology efforts in general, and tools for designing engineered mammalian functions in particular are also becoming available [118-120]. Some software is an extension of innovations pioneered in microbial systems and enables the design of complex circuits and forward-engineering to achieve desirable circuit performance [121]. Other tools focus explicitly on the challenge of achieving predictable levels of gene expression for particular systems, which dovetails with the discussion in the previous section of this review. For example, Beal et al. developed a model of RNA replicon-based gene expression, which correctly predicts gene expression profiles over time, spanning four orders of magnitude, from either single or multi- replicon systems [49]. Altogether, these examples illustrate the essential role that computational tools will likely play in both the design and analysis of engineered cellular functions. How these approaches may best be integrated with clinical data, including those that reflect the types of heterogeneity depicted in Figure 2, remains an open question and substantial opportunity, particularly as clinical experience with engineered cell-based therapies accumulates.

\subsection{Opportunities for engineering robust cell performance}

Even a cell-based therapy that performs well in some patients may confer undesired effects or exhibit performance variation, (i.e., due to inter-donor or inter-recipient heterogeneity), which may necessitate intervention post-administration. Implementing external or 'remote' control of engineered cells achieves this goal by sacrificing some aspects of autonomous therapeutic function in favor of the capacity to regulate therapeutic activity in response to any number of clinically observable variables. For example, a riboswitch-based platform was used to control $\mathrm{T}$ cell proliferation via the expression of a stimulatory cytokine, IL-2, in response to the 
small molecule theophylline; such an approach could ultimately enable physicians to fine-tune the balance between safety and efficacy in cancer immunotherapy [122]. The obesity control device discussed above used a similar strategy, enabling a physician to administer phloretin to disable the device if needed [8]. One consideration of particular relevance for translation of external control strategies is the choice the administered ligand. Drug-like ligands such as rapamycin and its analogs have been used to induce split protein reconstitution to control fluorescence [123], enzymatic activity [45], and genome editing [124, 125], although some such compounds also target mTOR (mammalian target of rapamycin) and thus confer side effects. Vitamins such as vitamin-H (biotin) can be used in the place of drugs to activate aptamer switches or engineered proteins [11, 126], although dietary biotin sources may complicate such a control strategy. Altogether, the externally-controlled system that has been most extensively tested in the clinic is Intrexon's RheoSwitch technology, which originally used a non-steroidal analog of the insect hormone ecdysone as a ligand and has subsequently been diversified to include several orthogonal ligand-sensor pairs [127, 128]. Such external control strategies have also been developed for CAR T cell therapies. Safety switches have been built into engineered CAR T cells, whereby small molecule-induced expression of caspase 9 initiates apoptosis in these engineered cells should complications arise, including uncontrolled proliferation [129]. External control of engineered cell therapies may be particularly useful in early trials of a strategy, when the learning curve is steep, and as a safety break feature even for more mature therapies. Ultimately, safety, efficacy, and tunability may all benefit from combining external control with technologies enabling the engineered therapeutic to sense more relevant aspects of host physiology.

Given the promise of CAR T cell therapy for cancer and both successes and shortcomings to date, one key opportunity for improving therapeutic outcomes is the development of such integrated strategies for better conferring spatiotemporal control over when the engineered T cells become activated - for example, to discriminate tumor sites from healthy tissue. While standard CAR strategies involve a single receptor, an engineered cell can be programmed to consider more than one environmental signal by engineering the cell to express more than one engineered receptor. One such strategy for temporary blocking $T$ cell activation in the presence of healthy tissue is to express both an antigen-reactive CAR and an inhibitory CAR (iCAR), for which binding to a "safe" antigen recruits domains that inhibit downstream TCR signaling [32]. Such cells are activated by the recognition of tumor antigens unless the safe antigen is also present. This strategy may be particularly effective when offtarget effects are known to occur in specific tissues, since implementation of this approach requires specification of both a tumor antigen and a particular safe antigen. T cells have also been engineered to execute logical evaluation of multiple extracellular cues [130]. For example, an AND gate was constructed by engineering cells to express two distinct antigen-specific CARs, one of which conferred suboptimal signaling and the other of which contributed only costimulatory domains, such that maximal $\mathrm{T}$ cell activation was observed only when both antigens were recognized [35]. In each of these examples, an inherent goal was minimizing intra-recipient heterogeneity by promoting robust activation of transplanted cells at the disease site and preventing activation of these cells at other sites within the body.

In principle, the aforementioned approaches could be expanded to address specific clinical needs. Temporal control may be enhanced by using a split CAR design, such that TCR signaling is contingent upon the administration of a small molecule that mediates reconstitution of a functional receptor [33]. CAR variants could be further multiplexed to evaluate more than two cues and thereby interrogate the environment in greater detail. Similarly, non-CAR receptors such as MESA [42] and/or syn-Notch receptors [43, 44] could be integrated to condition transgene expression on the presence or absence of specific extracellular cues. Such an approach could conceivably be used to overcome some sources of inter-recipient and interdonor heterogeneity as well, for example by tailoring therapeutic activity through interrogating 
the tumor microenvironment in each patient. For example, the capabilities described above could be used to engineer a cell-based therapy to activate and expand most robustly in highly immunosuppressed environments or patients, while activation and expansion could be moderated in the context of less pronounced immunosuppression in order to increase safety. In general, balancing such complexity with other aspects of performance and manufacturing considerations are active areas of research that are likely to leverage innovations in cellular engineering technologies discussed in previous sections.

\section{Conclusions and future outlook}

The field of cell-based therapy has grown substantially over the past decade, and there are now hundreds of therapies in clinical trials, which increasingly include the engineered mammalian cell therapies considered here [131]. Given the recent and dramatic clinical successes of CAR T cell therapies for cancer, in particular, the promise of engineered cellbased therapies is now incontrovertible. Fully realizing the potential of cell-based therapies will require developing new methodologies for designing, evaluating, and manufacturing such products.

First, although the synthetic biology toolbox now includes a large number of potential sensors and outputs, connecting multiple such parts to generate a translatable cell-based device, to perform complex synthetic sensing and signal processing for example, remains challenging. While the rapidly decreasing cost of DNA synthesis and the development of modular molecular biology schemes have greatly simplified the construction of novel genetic ensembles, implementing such an ensemble in a clinically-translatable cell type is often still challenging. As discussed in this review, a central feature of this challenge is the poorly understood connection between the mode of device implementation (e.g., the vehicle for gene delivery and the cell type in which the device is implemented) and intuitively important contributors to device performance in the form of the various modes of heterogeneity discussed here. Inherent in this challenge is the need to better understand the tradeoffs between device complexity and robust performance. Exploring these connections is an important priority for future investigations.

Second, achieving cell-based device performance that is both safe and effective may require both tools and strategies for utilizing external control in an analog fashion. To date, external control of cell-based devices has been largely (although not entirely) demonstrated to operate effectively in a digital fashion - administration of a small molecule may license the activation of a cell-based device or, alternatively, induce self-destruction of a cell-based device as a safety feature. While some of the same parts may be used to confer analog control of device performance to tune functions, utilizing this capability requires both an understanding and characterization of device performance (particularly in the context of the heterogeneity discussed in this review) and the development of clinical experience with the control of such devices in vivo. For example, whether control strategies that have been applied to control mechanical insulin pumps in response to blood glucose levels may apply to the control of cellbased devices is an attractive but relatively untested prospect. Therefore, investigating the potential to tune cell-based therapy performance via external control should be prioritized to both facilitate the clinical evaluation of novel strategies and, ultimately, improve safety and efficacy for patients.

Finally, as increasing numbers of engineered cell-based therapies approach the clinic, new manufacturing techniques may be necessary to make production more facile and costeffective. One solution may be to move away from patient derived cells toward non-autologous cell sources, such as cell lines engineered to be immunologically inert, potentially enabling the generation of off-the-shelf cell therapeutics for some applications. Better understanding the connection between device performance and manufacturing-oriented choices, such as the use 
of autologous cells vs. "universal donor" lines, would help to prioritize avenues for further process and product development. While several distinct manufacturing strategies are currently being investigated through the commercialization of CAR $\mathrm{T}$ cell therapies, a systematic investigation of these considerations would dovetail with forthcoming insights that these commercial efforts are likely to generate. Overall, the observation that each of the pressing needs highlighted here is of a distinctly translational nature bespeaks the fact that engineered cell-based therapies are now poised to significantly impact clinical practice and benefit patients. 


\section{Acknowledgements}

KAS was supported in part by National Institutes of Health T32 Training Grant GM 008449 through Northwestern University's Biotechnology Training Program and by the Defense Advanced Research Projects Agency, Award number W911NF-11-2-0066 (to JNL). No funding sources had any involvement in the writing of this manuscript. The human silhouette image (Fig. 2 ), was generated by Freepix and is used here under a creative common license. 


\section{References}

[1] M. Kalos, C.H. June, Adoptive T Cell Transfer for Cancer Immunotherapy in the Era of Synthetic Biology, Immunity, 39 (2013) 49-60.

[2] J.F. Miller, M. Sadelain, The journey from discoveries in fundamental immunology to cancer immunotherapy, Cancer Cell, 27 (2015) 439-449.

[3] C. Pinero-Lambea, D. Ruano-Gallego, L.A. Fernandez, Engineered bacteria as therapeutic agents, Curr Opin Biotech, 35 (2015) 94-102.

[4] J. Claesen, M.A. Fischbach, Synthetic Microbes As Drug Delivery Systems, Acs Synth Biol, 4 (2015) 358-364.

[5] J. Chappell, K.E. Watters, M.K. Takahashi, J.B. Lucks, A renaissance in RNA synthetic biology: new mechanisms, applications and tools for the future, Current opinion in chemical biology, 28 (2015) 47-56.

[6] V. Stein, K. Alexandrov, Synthetic protein switches: design principles and applications, Trends Biotechnol, 33 (2015) 101-110.

[7] C. Kemmer, M. Gitzinger, M. Daoud-El Baba, V. Djonov, J. Stelling, M. Fussenegger, Selfsufficient control of urate homeostasis in mice by a synthetic circuit, Nat Biotechnol, 28 (2010) 355-U382.

[8] K. Rossger, G. Charpin-El-Hamri, M. Fussenegger, A closed-loop synthetic gene circuit for the treatment of diet-induced obesity in mice, Nat Commun, 4 (2013).

[9] K. Rossger, G. Charpin-El-Hamri, M. Fussenegger, Bile acid-controlled transgene expression in mammalian cells and mice, Metab Eng, 21 (2014) 81-90.

[10] W.D. Wang, Z.T. Chen, B.G. Kang, R. Li, Construction of an artificial intercellular communication network using the nitric oxide signaling elements in mammalian cells, Experimental cell research, 314 (2008) 699-706.

[11] W. Weber, W. Bacchus, M. Daoud-El Baba, M. Fussenegger, Vitamin H-regulated transgene expression in mammalian cells, Nucleic Acids Res, 35 (2007) e116.

[12] C.M. Wright, R.C. Wright, J.R. Eshleman, M. Ostermeier, A protein therapeutic modality founded on molecular regulation, P Natl Acad Sci USA, 108 (2011) 16206-16211.

[13] S.J. Culler, K.G. Hoff, C.D. Smolke, Reprogramming cellular behavior with RNA controllers responsive to endogenous proteins, Science, 330 (2010) 1251-1255.

[14] A. Carvalho, D.B. Menendez, V.R. Senthivel, T. Zimmermann, L. Diambra, M. Isalan, Genetically Encoded Sender-Receiver System in 3D Mammalian Cell Culture, Acs Synth Biol, 3 (2014) 264-272.

[15] B.R. Conklin, E.C. Hsiao, S. Claeysen, A. Dumuis, S. Srinivasan, J.R. Forsayeth, J.M. Guettier, W.C. Chang, Y. Pei, K.D. McCarthy, R.A. Nissenson, J. Wess, J. Bockaert, B.L. Roth, Engineering GPCR signaling pathways with RASSLs, Nature methods, 5 (2008) 673-678.

[16] C.A. Sarkar, I. Dodevski, M. Kenig, S. Dudli, A. Mohr, E. Hermans, A. Pluckthun, Directed evolution of a $\mathrm{G}$ protein-coupled receptor for expression, stability, and binding selectivity, Proc Natl Acad Sci U S A, 105 (2008) 14808-14813.

[17] B.N. Armbruster, X. Li, M.H. Pausch, S. Herlitze, B.L. Roth, Evolving the lock to fit the key to create a family of $G$ protein-coupled receptors potently activated by an inert ligand, $P$ Natl Acad Sci USA, 104 (2007) 5163-5168.

[18] J. Wess, K. Nakajima, S. Jain, Novel designer receptors to probe GPCR signaling and physiology, Trends Pharmacol Sci, 34 (2013) 385-392.

[19] Y. Pei, S. Dong, B.L. Roth, Generation of designer receptors exclusively activated by designer drugs (DREADDs) using directed molecular evolution, Current protocols in neuroscience / editorial board, Jacqueline N. Crawley ... [et al.], Chapter 4 (2010) Unit 433. [20] B.A. Irving, A. Weiss, The Cytoplasmic Domain of the T-Cell Receptor Zeta-Chain Is Sufficient to Couple to Receptor-Associated Signal Transduction Pathways, Cell, 64 (1991) 891 901. 
[21] G. Gross, T. Waks, Z. Eshhar, Expression of Immunoglobulin-T-Cell Receptor Chimeric Molecules as Functional Receptors with Antibody-Type Specificity, P Natl Acad Sci USA, 86 (1989) 10024-10028.

[22] B. Savoldo, C.A. Ramos, E. Liu, M.P. Mims, M.J. Keating, G. Carrum, R.T. Kamble, C.M. Bollard, A.P. Gee, Z. Mei, H. Liu, B. Grilley, C.M. Rooney, H.E. Heslop, M.K. Brenner, G. Dotti, CD28 costimulation improves expansion and persistence of chimeric antigen receptor-modified T cells in lymphoma patients, The Journal of clinical investigation, 121 (2011) 1822-1826.

[23] H.M. Finney, A.D. Lawson, C.R. Bebbington, A.N. Weir, Chimeric receptors providing both primary and costimulatory signaling in $\mathrm{T}$ cells from a single gene product, Journal of immunology, 161 (1998) 2791-2797.

[24] J.N. Kochenderfer, M.E. Dudley, S.A. Feldman, W.H. Wilson, D.E. Spaner, I. Maric, M. Stetler-Stevenson, G.Q. Phan, M.S. Hughes, R.M. Sherry, J.C. Yang, U.S. Kammula, L. Devillier, R. Carpenter, D.A. Nathan, R.A. Morgan, C. Laurencot, S.A. Rosenberg, B-cell depletion and remissions of malignancy along with cytokine-associated toxicity in a clinical trial of anti-CD19 chimeric-antigen-receptor-transduced T cells, Blood, 119 (2012) 2709-2720.

[25] R.J. Brentjens, I. Riviere, J.H. Park, M.L. Davila, X.Y. Wang, J. Stefanski, C. Taylor, R. Yeh, S. Bartido, O. Borquez-Ojeda, M. Olszewska, Y. Bernal, H. Pegram, M. Przybylowski, D. Hollyman, Y. Usachenko, D. Pirraglia, J. Hosey, E. Santos, E. Halton, P. Maslak, D. Scheinberg, J. Jurcic, M. Heaney, G. Heller, M. Frattini, M. Sadelain, Safety and persistence of adoptively transferred autologous CD19-targeted T cells in patients with relapsed or chemotherapy refractory B-cell leukemias, Blood, 118 (2011) 4817-4828.

[26] L. Duval, H. Schmidt, K. Kaltoft, K. Fode, J.J. Jensen, S.M. Sorensen, M.I. Nishimura, H. von der Maase, Adoptive transfer of allogeneic cytotoxic T lymphocytes equipped with a HLAA2 restricted MART-1 T-cell receptor: a phase I trial in metastatic melanoma, Clinical Cancer Research, 12 (2006) 1229-1236.

[27] Q. Ma, M. Safar, E. Holmes, Y. Wang, A.L. Boynton, R.P. Junghans, Anti-prostate specific membrane antigen designer T cells for prostate cancer therapy, The Prostate, 61 (2004) 12-25. [28] J.A. Westwood, M.J. Smyth, M.W.L. Teng, M. Moeller, J.A. Trapani, A.M. Scott, F.E. Smyth, G.A. Cartwright, B.E. Power, D. Honemann, H.M. Prince, P.K. Darcy, M.H. Kershaw, Adoptive transfer of $T$ cells modified with a humanized chimeric receptor gene inhibits growth of Lewis-Y-expressing tumors in mice, P Natl Acad Sci USA, 102 (2005) 19051-19056.

[29] Z. Sharifzadeh, F. Rahbarizadeh, M.A. Shokrgozar, D. Ahmadvand, F. Mahboudi, F.R. Jamnani, S.M. Moghimi, Genetically engineered T cells bearing chimeric nanoconstructed receptors harboring TAG-72-specific camelid single domain antibodies as targeting agents, Cancer Lett, 334 (2013) 237-244.

[30] S.L. Maude, N. Frey, P.A. Shaw, R. Aplenc, D.M. Barrett, N.J. Bunin, A. Chew, V.E. Gonzalez, Z.H. Zheng, S.F. Lacey, Y.D. Mahnke, J.J. Melenhorst, S.R. Rheingold, A. Shen, D.T. Teachey, B.L. Levine, C.H. June, D.L. Porter, S.A. Grupp, Chimeric Antigen Receptor T Cells for Sustained Remissions in Leukemia, New Engl J Med, 371 (2014) 1507-1517.

[31] M.L. Davila, I. Riviere, X.Y. Wang, S. Bartido, J. Park, K. Curran, S.S. Chung, J. Stefanski, O. Borquez-Ojeda, M. Olszewska, J.R. Qu, T. Wasielewska, Q. He, M. Fink, H. Shinglot, M. Youssif, M. Satter, Y.Z. Wang, J. Hosey, H. Quintanilla, E. Halton, Y. Bernal, D.C.G. Bouhassira, M.E. Arcila, M. Gonen, G.J. Roboz, P. Maslak, D. Douer, M.G. Frattini, S. Giralt, M. Sadelain, R. Brentjens, Efficacy and Toxicity Management of 19-28z CAR T Cell Therapy in B Cell Acute Lymphoblastic Leukemia, Sci Transl Med, 6 (2014).

[32] V.D. Fedorov, M. Themeli, M. Sadelain, PD-1-and CTLA-4-Based Inhibitory Chimeric Antigen Receptors (iCARs) Divert Off-Target Immunotherapy Responses, Sci TransI Med, 5 (2013).

[33] C.Y. Wu, K.T. Roybal, E.M. Puchner, J. Onuffer, W.A. Lim, Remote control of therapeutic T cells through a small molecule-gated chimeric receptor, Science, (2015). 
[34] K.C. Straathof, M.A. Pule, P. Yotnda, G. Dotti, E.F. Vanin, M.K. Brenner, H.E. Heslop, D.M. Spencer, C.M. Rooney, An inducible caspase 9 safety switch for T-cell therapy, Blood, 105 (2005) 4247-4254.

[35] C.C. Kloss, M. Condomines, M. Cartellieri, M. Bachmann, M. Sadelain, Combinatorial antigen recognition with balanced signaling promotes selective tumor eradication by engineered T cells, Nat Biotechnol, 31 (2013) 71-75.

[36] L. Zhang, S.P. Kerkar, Z.Y. Yu, Z.L. Zheng, S.C. Yang, N.P. Restifo, S.A. Rosenberg, R.A. Morgan, Improving Adoptive T Cell Therapy by Targeting and Controlling IL-12 Expression to the Tumor Environment, Mol Ther, 19 (2011) 751-759.

[37] L.B. John, M.H. Kershaw, P.K. Darcy, Blockade of PD-1 immunosuppression boosts CAR T-cell therapy, Oncoimmunology, 2 (2013).

[38] K. Tamada, D. Geng, Y. Sakoda, N. Bansal, R. Srivastava, Z. Li, Redirecting GeneModified T Cells toward Various Cancer Types Using Tagged Antibodies (vol 18, pg 6436, 2012), Clinical Cancer Research, 19 (2013) 951-951.

[39] K. Urbanska, E. Lanitis, M. Poussin, R.C. Lynn, B.P. Gavin, S. Kelderman, J. Yu, N. Scholler, D.J. Powell, A Universal Strategy for Adoptive Immunotherapy of Cancer through Use of a Novel T-cell Antigen Receptor, Cancer Res, 72 (2012) 1844-1852.

[40] G. Barnea, W. Strapps, G. Herrada, Y. Berman, J. Ong, B. Kloss, R. Axel, K.J. Lee, The genetic design of signaling cascades to record receptor activation, Proc Natl Acad Sci U S A, 105 (2008) 64-69.

[41] H. Ye, M. Daoud-El Baba, R.W. Peng, M. Fussenegger, A synthetic optogenetic transcription device enhances blood-glucose homeostasis in mice, Science, 332 (2011) 15651568.

[42] N.M. Daringer, R.M. Dudek, K.A. Schwarz, J.N. Leonard, Modular Extracellular Sensor Architecture for Engineering Mammalian Cell-based Devices, Acs Synth Biol, 3 (2014) 892-902. [43] L. Morsut, K.T. Roybal, X. Xiong, R.M. Gordley, S.M. Coyle, M. Thomson, W.A. Lim, Engineering Customized Cell Sensing and Response Behaviors Using Synthetic Notch Receptors, Cell, 164 (2016) 780-791.

[44] K.T. Roybal, L.J. Rupp, L. Morsut, W.J. Walker, K.A. McNally, J.S. Park, W.A. Lim, Precision Tumor Recognition by T Cells With Combinatorial Antigen-Sensing Circuits, Cell, 164 (2016) 770-779.

[45] M.C. Wehr, R. Laage, U. Bolz, T.M. Fischer, S. Grunewald, S. Scheek, A. Bach, K.A. Nave, M.J. Rossner, Monitoring regulated protein-protein interactions using split TEV, Nature methods, 3 (2006) 985-993.

[46] E.C. Schwartz, L. Saez, M.W. Young, T.W. Muir, Post-translational enzyme activation in an animal via optimized conditional protein splicing, Nature chemical biology, 3 (2007) 50-54.

[47] Y. Xu, P.K. Darcy, M.H. Kershaw, Tumor-specific dendritic cells generated by genetic redirection of Toll-like receptor signaling against the tumor-associated antigen, erbB2, Cancer Gene Ther, 14 (2007) 773-780.

[48] O. Andries, T. Kitada, K. Bodner, N.N. Sanders, R. Weiss, Synthetic biology devices and circuits for RNA-based 'smart vaccines': a propositional review, Expert Rev Vaccines, 14 (2015) 313-331.

[49] J. Beal, T.E. Wagner, T. Kitada, O. Azizgolshani, J.M. Parker, D. Densmore, R. Weiss, Model-Driven Engineering of Gene Expression from RNA Replicons, Acs Synth Biol, 4 (2015) 48-56.

[50] http://www.darpa.mil/program/autonomous-diagnostics-to-enable-prevention-andTherapeutics.

[51] S. El Andaloussi, I. Mager, X.O. Breakefield, M.J.A. Wood, Extracellular vesicles: biology and emerging therapeutic opportunities, Nat Rev Drug Discov, 12 (2013) 347-357. 
[52] B. Gyorgy, M.E. Hung, X.O. Breakefield, J.N. Leonard, Therapeutic applications of extracellular vesicles: clinical promise and open questions, Annu Rev Pharmacol Toxicol, 55 (2015) 439-464.

[53] A. Hoshino, B. Costa-Silva, T.-L. Shen, G. Rodrigues, A. Hashimoto, M. Tesic Mark, H. Molina, S. Kohsaka, A. Di Giannatale, S. Ceder, S. Singh, C. Williams, N. Soplop, K. Uryu, L. Pharmer, T. King, L. Bojmar, A.E. Davies, Y. Ararso, T. Zhang, H. Zhang, J. Hernandez, J.M. Weiss, V.D. Dumont-Cole, K. Kramer, L.H. Wexler, A. Narendran, G.K. Schwartz, J.H. Healey, P. Sandstrom, K. Jørgen Labori, E.H. Kure, P.M. Grandgenett, M.A. Hollingsworth, M. de Sousa, S. Kaur, M. Jain, K. Mallya, S.K. Batra, W.R. Jarnagin, M.S. Brady, O. Fodstad, V. Muller, K. Pantel, A.J. Minn, M.J. Bissell, B.A. Garcia, Y. Kang, V.K. Rajasekhar, C.M. Ghajar, I. Matei, H. Peinado, J. Bromberg, D. Lyden, Tumour exosome integrins determine organotropic metastasis, Nature, advance online publication (2015).

[54] B. Costa-Silva, N.M. Aiello, A.J. Ocean, S. Singh, H. Zhang, B.K. Thakur, A. Becker, A. Hoshino, M.T. Mark, H. Molina, J. Xiang, T. Zhang, T.M. Theilen, G. Garcia-Santos, C. Williams, Y. Ararso, Y. Huang, G. Rodrigues, T.L. Shen, K.J. Labori, I.M. Lothe, E.H. Kure, J. Hernandez, A. Doussot, S.H. Ebbesen, P.M. Grandgenett, M.A. Hollingsworth, M. Jain, K. Mallya, S.K. Batra, W.R. Jarnagin, R.E. Schwartz, I. Matei, H. Peinado, B.Z. Stanger, J. Bromberg, D. Lyden, Pancreatic cancer exosomes initiate pre-metastatic niche formation in the liver, Nat Cell Biol, 17 (2015) 816-826.

[55] A.S. Azmi, B. Bao, F.H. Sarkar, Exosomes in cancer development, metastasis, and drug resistance: a comprehensive review, Cancer Metastasis Rev, 32 (2013) 623-642.

[56] H. Peinado, M. Aleckovic, S. Lavotshkin, I. Matei, B. Costa-Silva, G. Moreno-Bueno, M. Hergueta-Redondo, C. Williams, G. Garcia-Santos, C. Ghajar, A. Nitadori-Hoshino, C. Hoffman, K. Badal, B.A. Garcia, M.K. Callahan, J. Yuan, V.R. Martins, J. Skog, R.N. Kaplan, M.S. Brady, J.D. Wolchok, P.B. Chapman, Y. Kang, J. Bromberg, D. Lyden, Melanoma exosomes educate bone marrow progenitor cells toward a pro-metastatic phenotype through MET, Nat Med, 18 (2012) 883-891.

[57] M. Kumar, B. Keller, N. Makalou, R.E. Sutton, Systematic determination of the packaging limit of lentiviral vectors, Hum Gene Ther, 12 (2001) 1893-1905.

[58] P.L. Sinn, S.L. Sauter, P.L. McCray, Gene Therapy Progress and Prospects: Development of improved lentiviral and retroviral vectors - design, biosafety, and production, Gene Ther, 12 (2005) 1089-1098.

[59] J. Matrai, M.K.L. Chuah, T. VandenDriessche, Recent Advances in Lentiviral Vector Development and Applications (vol 18, pg 477, 2010), Mol Ther, 18 (2010) 1055-1055.

[60] K. Breckpot, J.L. Aerts, K. Thielemans, Lentiviral vectors for cancer immunotherapy: transforming infectious particles into therapeutics, Gene Ther, 14 (2007) 847-862.

[61] J. He, Q. Yang, L.J. Chang, Dynamic DNA methylation and histone modifications contribute to lentiviral transgene silencing in murine embryonic carcinoma cells, J Virol, 79 (2005) 1349713508.

[62] A. Hofmann, B. Kessler, S. Ewerling, A. Kabermann, G. Brem, E. Wolf, A. Pfeifer, Epigenetic regulation of lentiviral transgene vectors in a large animal model, Mol Ther, 13 (2006) 59-66.

[63] Y. Yamagata, V. Parietti, D. Stockholm, G. Corre, C. Poinsignon, N. Touleimat, D. Delafoy, C. Besse, J. Tost, A. Galy, A. Paldi, Lentiviral Transduction of CD34(+) Cells Induces GenomeWide Epigenetic Modifications, Plos One, 7 (2012).

[64] Z.J. Wu, H.Y. Yang, P. Colosi, Effect of Genome Size on AAV Vector Packaging, Mol Ther, 18 (2010) 80-86.

[65] R.J. Samulski, N. Muzyczka, AAV-Mediated Gene Therapy for Research and Therapeutic Purposes, Ann Rev Virol, 1 (2014) 427-451. 
[66] Z. Yan, Y. Zhang, D. Duan, J.F. Engelhardt, Trans-splicing vectors expand the utility of adeno-associated virus for gene therapy, Proceedings of the National Academy of Sciences, 97 (2000) 6716-6721.

[67] R.M. Kotin, M. Siniscalco, R.J. Samulski, X.D. Zhu, L. Hunter, C.A. Laughlin, S.

McLaughlin, N. Muzyczka, M. Rocchi, K.I. Berns, Site-specific integration by adeno-associated virus, Proc Natl Acad Sci U S A, 87 (1990) 2211-2215.

[68] R.J. Samulski, X. Zhu, X. Xiao, J.D. Brook, D.E. Housman, N. Epstein, L.A. Hunter, Targeted integration of adeno-associated virus (AAV) into human chromosome 19, EMBO J, 10 (1991) 3941-3950.

[69] P. Ward, C.E. Walsh, Targeted integration of a rAAV vector into the AAVS1 region, Virology, 433 (2012) 356-366.

[70] F. Mingozzi, K.A. High, Immune responses to AAV vectors: overcoming barriers to successful gene therapy, Blood, 122 (2013) 23-36.

[71] I. Alexander, D. Russell, The Potential of AAV-Mediated Gene Targeting for Gene and Cell Therapy Applications, Curr Stem Cell Rep, 1 (2015) 16-22.

[72] Z. Izsvak, Z. Ivics, R.H. Plasterk, Sleeping Beauty, a wide host-range transposon vector for genetic transformation in vertebrates, Journal of molecular biology, 302 (2000) 93-102.

[73] C.S. Hackett, A.M. Geurts, P.B. Hackett, Predicting preferential DNA vector insertion sites: implications for functional genomics and gene therapy, Genome biology, 8 Suppl 1 (2007) S12. [74] C.W. Park, B.T. Kren, D.A. Largaespada, C.J. Steer, DNA methylation of Sleeping Beauty with transposition into the mouse genome, Genes to cells : devoted to molecular \& cellular mechanisms, 10 (2005) 763-776.

[75] E.L. Aronovich, R.S. Mclvor, P.B. Hackett, The Sleeping Beauty transposon system: a nonviral vector for gene therapy, Human molecular genetics, 20 (2011) R14-20.

[76] T. Okuyama, R.M. Huber, W. Bowling, R. Pearline, S.C. Kennedy, M.W. Flye, K.P. Ponder, Liver-directed gene therapy: A retroviral vector with a complete LTR and the ApoE enhanceralpha(1)-antitrypsin promoter dramatically increases expression of human alpha(1)-antitrypsin in vivo, Hum Gene Ther, 7 (1996) 637-645.

[77] Z. Ivics, A. Katzer, E.E. Stuwe, D. Fiedler, S. Knespel, Z. Izsvak, Targeted Sleeping Beauty transposition in human cells, Mol Ther, 15 (2007) 1137-1144.

[78] S.R. Yant, Y. Huang, B. Akache, M.A. Kay, Site-directed transposon integration in human cells, Nucleic Acids Research, 35 (2007).

[79] H. Singh, J.S. Moyes, M.H. Huls, L.J. Cooper, Manufacture of T cells using the Sleeping Beauty system to enforce expression of a CD19-specific chimeric antigen receptor, Cancer Gene Ther, 22 (2015) 95-100.

[80] T. Gaj, C.A. Gersbach, C.F. Barbas, ZFN, TALEN, and CRISPR/Cas-based methods for genome engineering, Trends Biotechnol, 31 (2013) 397-405.

[81] H. Kim, J.S. Kim, A guide to genome engineering with programmable nucleases, Nat Rev Genet, 15 (2014) 321-334.

[82] L.S. Qi, M.H. Larson, L.A. Gilbert, J.A. Doudna, J.S. Weissman, A.P. Arkin, W.A. Lim, Repurposing CRISPR as an RNA-guided platform for sequence-specific control of gene expression, Cell, 152 (2013) 1173-1183.

[83] L. Cong, F.A. Ran, D. Cox, S. Lin, R. Barretto, N. Habib, P.D. Hsu, X. Wu, W. Jiang, L.A. Marraffini, F. Zhang, Multiplex genome engineering using CRISPR/Cas systems, Science, 339 (2013) 819-823.

[84] V. Pattanayak, S. Lin, J.P. Guilinger, E.B. Ma, J.A. Doudna, D.R. Liu, High-throughput profiling of off-target DNA cleavage reveals RNA-programmed Cas9 nuclease specificity, Nat Biotechnol, 31 (2013) 839-+.

[85] Y.F. Fu, J.A. Foden, C. Khayter, M.L. Maeder, D. Reyon, J.K. Joung, J.D. Sander, Highfrequency off-target mutagenesis induced by CRISPR-Cas nucleases in human cells, Nat Biotechnol, 31 (2013) 822-+. 
[86] F.A. Ran, P.D. Hsu, C.Y. Lin, J.S. Gootenberg, S. Konermann, A.E. Trevino, D.A. Scott, A. Inoue, S. Matoba, Y. Zhang, F. Zhang, Double nicking by RNA-guided CRISPR Cas9 for enhanced genome editing specificity, Cell, 154 (2013) 1380-1389.

[87] D. Kim, S. Bae, J. Park, E. Kim, S. Kim, H.R. Yu, J. Hwang, J.I. Kim, J.S. Kim, Digenomeseq: genome-wide profiling of CRISPR-Cas9 off-target effects in human cells, Nature methods, 12 (2015) 237-+.

[88] J.G. Doench, E. Hartenian, D.B. Graham, Z. Tothova, M. Hegde, I. Smith, M. Sullender, B.L. Ebert, R.J. Xavier, D.E. Root, Rational design of highly active sgRNAs for CRISPR-Cas9mediated gene inactivation, Nat Biotechnol, 32 (2014) 1262-U1130.

[89] S. Kiani, A. Chavez, M. Tuttle, R.N. Hall, R. Chari, D. Ter-Ovanesyan, J. Qian, B.W. Pruitt, J. Beal, S. Vora, J. Buchthal, E.J. Kowal, M.R. Ebrahimkhani, J.J. Collins, R. Weiss, G. Church, Cas9 gRNA engineering for genome editing, activation and repression, Nature methods, 12 (2015) 1051-1054.

[90] F. Heigwer, G. Kerr, M. Boutros, E-CRISP: fast CRISPR target site identification, Nature methods, 11 (2014) 122-124.

[91] H. Xu, T. Xiao, C.H. Chen, W. Li, C.A. Meyer, Q. Wu, D. Wu, L. Cong, F. Zhang, J.S. Liu, M. Brown, X.S. Liu, Sequence determinants of improved CRISPR sgRNA design, Genome research, 25 (2015) 1147-1157.

[92] P. Mali, J. Aach, P.B. Stranges, K.M. Esvelt, M. Moosburner, S. Kosuri, L. Yang, G.M. Church, CAS9 transcriptional activators for target specificity screening and paired nickases for cooperative genome engineering, Nat Biotech, 31 (2013) 833-838.

[93] S.W. Cho, S. Kim, Y. Kim, J. Kweon, H.S. Kim, S. Bae, J.S. Kim, Analysis of off-target effects of CRISPR/Cas-derived RNA-guided endonucleases and nickases, Genome research, 24 (2014) 132-141.

[94] Y.F. Fu, J.D. Sander, D. Reyon, V.M. Cascio, J.K. Joung, Improving CRISPR-Cas nuclease specificity using truncated guide RNAs, Nat Biotechnol, 32 (2014) 279-284.

[95] S. Kim, D. Kim, S.W. Cho, J. Kim, J.S. Kim, Highly efficient RNA-guided genome editing in human cells via delivery of purified Cas9 ribonucleoproteins, Genome research, 24 (2014) 1012-1019.

[96] S. Ramakrishna, A.K. Dad, J. Beloor, R. Gopalappa, S.K. Lee, H. Kim, Gene disruption by cell-penetrating peptide-mediated delivery of Cas9 protein and guide RNA, Genome research, 24 (2014) 1020-1027.

[97] X. Duportet, L. Wroblewska, P. Guye, Y. Li, J. Eyquem, J. Rieders, T. Rimchala, G. Batt, R. Weiss, A platform for rapid prototyping of synthetic gene networks in mammalian cells, Nucleic Acids Res, 42 (2014) 13440-13451.

[98] B.R. Grimes, D. Schindelhauer, N.I. McGill, A. Ross, T.A. Ebersole, H.J. Cooke, Stable gene expression from a mammalian artificial chromosome, Embo Rep, 2 (2001) 910-914.

[99] K. Yoshimi, K. Tomizuka, T. Shinohara, Y. Kazuki, H. Yoshida, A. Ohguma, T. Yamamoto,

S. Tanaka, M. Oshimura, I. Ishida, Manipulation of human minichromosomes to carry greater than megabase-sized chromosome inserts, Nat Biotechnol, 18 (2000) 1086-1090.

[100] L. Rocchi, C. Braz, S. Cattani, A. Ramalho, S. Christan, M. Edlinger, F. Ascenzioni, A. Laner, S. Kraner, M. Amaral, D. Schindelhauer, Escherichia coli-Cloned CFTR Loci Relevant for Human Artificial Chromosome Therapy, Hum Gene Ther, 21 (2010) 1077-1092.

[101] N. Suzuki, T. Itou, Y. Hasegawa, T. Okazaki, M. Ikeno, Cell to cell transfer of the chromatin-packaged human beta-globin gene cluster, Nucleic Acids Research, 38 (2010). [102] A.M. Breman, C.M. Steiner, R.B. Slee, B.R. Grimes, Input DNA ratio determines copy number of the $33 \mathrm{~kb}$ factor IX gene on De Novo human artificial chromosomes, Mol Ther, 16 (2008) 315-323.

[103] Y. Kazuki, M. Hiratsuka, M. Takiguchi, M. Osaki, N. Kajitani, H. Hoshiya, K. Hiramatsu, T. Yoshino, K. Kazuki, C. Ishihara, S. Takehara, K. Higaki, M. Nakagawa, K. Takahashi, S. 
Yamanaka, M. Oshimura, Complete Genetic Correction of iPS Cells From Duchenne Muscular Dystrophy, Mol Ther, 18 (2010) 386-393.

[104] I.C. Berke, Y. Li, Y. Modis, Structural basis of innate immune recognition of viral RNA, Cell Microbiol, 15 (2013) 386-394.

[105] G.C. Han, Y. Li, J.N. Wang, R.X. Wang, G.J. Chen, L. Song, R.N. Xu, M. Yu, X.B. Wu, J.H. Qian, B.F. Shen, Active tolerance induction and prevention of autoimmune diabetes by immunogene therapy using recombinant adenoassociated virus expressing glutamic acid decarboxylase 65 peptide GAD(500-585), Journal of immunology, 174 (2005) 4516-4524. [106] J. Bryant, K.A. Hlavaty, X. Zhang, W.T. Yap, L. Zhang, L.D. Shea, X. Luo, Nanoparticle delivery of donor antigens for transplant tolerance in allogeneic islet transplantation,

Biomaterials, 35 (2014) 8887-8894.

[107] Z. Hunter, D.P. McCarthy, W.T. Yap, C.T. Harp, D.R. Getts, L.D. Shea, S.D. Miller, A Biodegradable Nanoparticle Platform for the Induction of Antigen-Specific Immune Tolerance for Treatment of Autoimmune Disease, Acs Nano, 8 (2014) 2148-2160.

[108] J.H. Shi, L. Kundrat, N. Pishesha, A. Bilate, C. Theile, T. Maruyama, S.K. Dougan, H.L. Ploegh, H.F. Lodish, Engineered red blood cells as carriers for systemic delivery of a wide array of functional probes, P Natl Acad Sci USA, 111 (2014) 10131-10136.

[109] V.R. Muzykantov, Drug delivery by red blood cells: vascular carriers designed by mother nature, Expert Opin Drug Del, 7 (2010) 403-427.

[110] M.D. Hoban, G.J. Cost, M.C. Mendel, Z. Romero, M.L. Kaufman, A.V. Joglekar, M. Ho, D. Lumaquin, D. Gray, G.R. Lill, A.R. Cooper, F. Urbinati, S. Senadheera, A. Zhu, P.Q. Liu, D.E. Paschon, L. Zhang, E.J. Rebar, A. Wilber, X.Y. Wang, P.D. Gregory, M.C. Holmes, A. Reik, R.P. Hollis, D.B. Kohn, Correction of the sickle cell disease mutation in human hematopoietic stem/progenitor cells, Blood, 125 (2015) 2597-2604.

[111] X.S. Huang, Y. Wang, W. Yan, C. Smith, Z.H. Ye, J. Wang, Y.X. Gao, L. Mendelsohn, L.Z. Cheng, Production of Gene-Corrected Adult Beta Globin Protein in Human Erythrocytes Differentiated From Patient iPSCs After Genome Editing of the Sickle Point Mutation, Stem Cells, 33 (2015) 1470-1479.

[112] C. May, S. Rivella, J. Callegari, G. Heller, K.M.L. Gaensler, L. Luzzatto, M. Sadelain, Therapeutic haemoglobin synthesis in beta-thalassaemic mice expressing lentivirus-encoded human beta-globin, Nature, 406 (2000) 82-86.

[113] C. May, S. Rivella, A. Chadburn, M. Sadelain, Successful treatment of murine betathalassemia intermedia by transfer of the human beta-globin gene, Blood, 99 (2002) 1902-1908.

[114] A. Levchenko, I. Nemenman, Cellular noise and information transmission, Curr Opin Biotech, 28 (2014) 156-164.

[115] R. Cheong, A. Rhee, C.J. Wang, I. Nemenman, A. Levchenko, Information Transduction Capacity of Noisy Biochemical Signaling Networks, Science, 334 (2011) 354-358.

[116] M. Tikhonov, S.C. Little, T. Gregor, Only accessible information is useful: insights from gradient-mediated patterning, R Soc Open Sci, 2 (2015) 150486.

[117] A.S. Hansen, E.K. O'Shea, Limits on information transduction through amplitude and frequency regulation of transcription factor activity, Elife, 4 (2015).

[118] M.A. Marchisio, J. Stelling, Computational design tools for synthetic biology, Curr Opin Biotech, 20 (2009) 479-485.

[119] J.T. MacDonald, C. Barnes, R.I. Kitney, P.S. Freemont, G.B.V. Stan, Computational design approaches and tools for synthetic biology, Integr Biol-Uk, 3 (2011) 97-108.

[120] M.H. Medema, R. van Raaphorst, E. Takano, R. Breitling, Computational tools for the synthetic design of biochemical pathways, Nat Rev Microbiol, 10 (2012) 191-202.

[121] N. Davidsohn, J. Beal, S. Kiani, A. Adler, F. Yaman, Y.Q. Li, Z. Xie, R. Weiss, Accurate Predictions of Genetic Circuit Behavior from Part Characterization and Modular Composition, Acs Synth Biol, 4 (2015) 673-681. 
[122] Y.Y. Chen, M.C. Jensen, C.D. Smolke, Genetic control of mammalian T-cell proliferation with synthetic RNA regulatory systems, Proceedings of the National Academy of Sciences, 107 (2010) 8531-8536.

[123] S. Cabantous, H.B. Nguyen, J.D. Pedelacq, F. Koraichi, A. Chaudhary, K. Ganguly, M.A. Lockard, G. Favre, T.C. Terwilliger, G.S. Waldo, A New Protein-Protein Interaction Sensor Based on Tripartite Split-GFP Association, Sci Rep-Uk, 3 (2013).

[124] B. Zetsche, S.E. Volz, F. Zhang, A split-Cas9 architecture for inducible genome editing and transcription modulation, Nat Biotechnol, 33 (2015) 139-142.

[125] A.V. Wright, S.H. Sternberg, D.W. Taylor, B.T. Staahl, J.A. Bardales, J.E. Kornfeld, J.A. Doudna, Rational design of a split-Cas9 enzyme complex, P Natl Acad Sci USA, 112 (2015) 2984-2989.

[126] W. Weber, C. Lienhart, M.D. Baba, M. Fussenegger, A biotin-triggered genetic switch in mammalian cells and mice, Metab Eng, 11 (2009) 117-124.

[127] S.R. Palli, M.Z. Kapitskaya, M.B. Kumar, D.E. Cress, Improved ecdysone receptor-based inducible gene regulation system, Eur J Biochem, 270 (2003) 1308-1315.

[128] J. Lessard, S.B. Aicha, A. Fournier, E. Calvo, E. Lavergne, M. Pelletier, C. Labrie, Characterization of the RSL1-dependent conditional expression system in LNCaP prostate cancer cells and development of a single vector format, Prostate, 67 (2007) 808-819.

[129] T. Gargett, M.P. Brown, The inducible caspase-9 suicide gene system as a "safety switch" to limit on-target, off-tumor toxicities of chimeric antigen receptor T cells, Front Pharmacol, 5 (2014).

[130] D. Chakravarti, W.W. Wong, Synthetic biology in cell-based cancer immunotherapy, Trends Biotechnol, 33 (2015) 449-461.

[131] http://celltrials.info/2014/03/02/trends-2011-2013/. 